\title{
Vertical REE profiles in water and DGT in the central Arctic Ocean
}

\author{
R. DAHLQVIST ${ }^{1}$, P. S. ANDERSSON ${ }^{2}$, J. INGRI $^{3}$ \\ AND D. PORCELLI ${ }^{1}$
}

${ }^{1}$ University of Oxford, Dept. of Earth Sciences, Oxford OX1 3PR, UK; Ralf.Dahlqvist@earth.ox.ac.uk

${ }^{2}$ Swedish Museum of Natural History, Lab. for Isotope Geology, Stockholm, Sweden; per.andersson@nrm.se ${ }^{3}$ Luleå University of Technology, Division of Applied Geology, Luleå, Sweden; johan.ingri@1tu.se

The first vertical REE concentration profiles from the central Arcitc Ocean $\left(88^{\circ} 27^{\prime} \mathrm{N}, 0^{\circ} 45^{\prime} \mathrm{W}\right)$ to combine data for filtered water samples with data for the labile REE fration collected with the in situ method of diffusive gradients in thin films (DGT) are presented here.

During a 3-week drift station in 2001 the pack ice was used as a plattform to provide ultra clean conditions for filtration, sampling of water, and deployment of DGT. The DGT-method is an in situ method which employs a hydrogel to collect labile and easily diffusible species from the natural seawater matrix.

REE concentrations for the filtered water samples show no clear trend in the top $200 \mathrm{~m}$ of the water column. Surface water $\mathrm{C}_{\mathrm{La}}$ is $\sim 75 \mathrm{pM}$. In contrast, results from the DGT deployments show a significant concentration increase towards the surface, with a factor of 2-3 for all REE. $\mathrm{C}_{\mathrm{La}}$ at $10 \mathrm{~m}$ and $200 \mathrm{~m}$ measured with DGT are $68 \mathrm{pM}$ and $26 \mathrm{pM}$ respectively. This indicates that the fraction of labile metal incrases towards the surface, which is contrary to the nutrient-like behavior observed for many trace elements in the oceans. We therefore conclude that a different mechanism controls the physico-chemical speciation of REE in central Arctic Ocean surface waters.

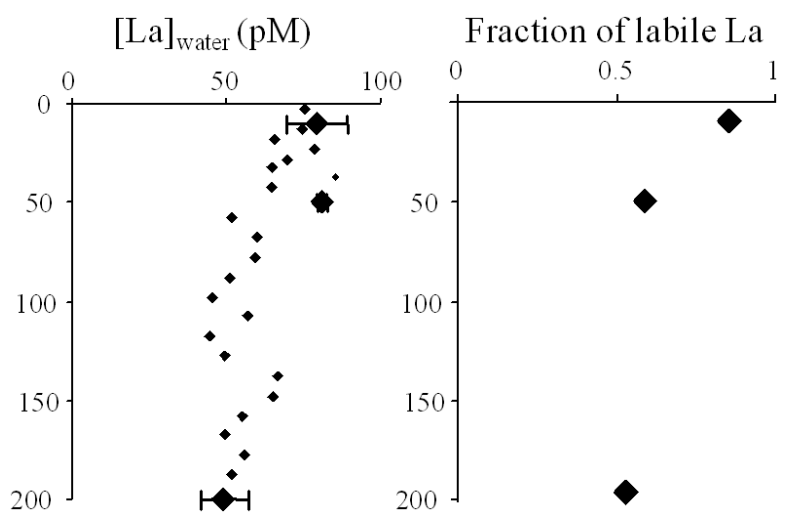

Results from the 2001 expedition are compared with published data, and with recently analyzed data from Bering Strait and the Chukchi Sea, which, through the trans polar drift, is a possible source for surface water in the central region of the Arctic Ocean. 